\title{
Developing Quantifiable Defect Record for Tall Building Envelop using Passive Infrared Thermography and Building Information Modelling
}

\author{
by Lydia S. Y. Chiu' ${ }^{1}$, Wallace W. L. Lai ${ }^{2}$, Miranda C. Y. Lui ${ }^{3}$ \\ ${ }^{1}$ The Hong Kong Polytechnic University, Hong Kong, sin-yau-lydia.chiu@polyu.edu.hk \\ 2 The Hong Kong Polytechnic University, Hong Kong, wallace.wai.lok.lai@polyu.edu.hk \\ ${ }_{3}$ MES Group Asia, Hong Kong, mirandalui@mesgroup.asia
}

\section{Abstract}

This ongoing project aims to develop a methodology for imaging and diagnosis of external wall debond of tall building envelop by adopting quantitative infrared thermography (IRT) in as-built building information model (BIM) based on point cloud technology. Thermal images of the building envelop are captured and ortho-correction is performed. The data obtained is then processed and exported as binary images indicating the location of debonds and combined with point cloud data and imported into BIM for health diagnosis of building envelop. The approach is similar to establishment of a regular track record of building envelop which is currently in vain.

\section{Background}

High rise buildings are one of the main features of Hong Kong. To ensure building safety, Hong Kong government has introduced the Mandatory Building Inspection Scheme (MBIS), which requires building owners of buildings aged 30 years or above to appoint a registered inspector to carry out building inspection [1]. Passive infrared thermography is one of the inspection techniques listed in the Code of Practice, and it is accredited by the Hong Kong Laboratory Accreditation Scheme [1,2]. It is a non-contact and non-destructive technique to detect embedded debonds in large scale inspection when compared to traditional detection methods including visual inspection, hammer-tapping test and pull-off tests [3].

In Hong Kong, adoption of BIM technology in capital works projects is encouraged by the government to enhance quality and decision making in maintenance planning [4]. BIM model could be used to develop a health record, where maintenance and inspection record are stored. In this project, a methodology is developed to adopt IRT into BIM to provide quantitative defect record which facilitates maintenance cost estimation.

\section{Literature review}

Infrared thermography is a common method used to detect temperature distribution on building envelop [5]. To detect debonds on building envelop, passive heat sources such as natural sunlight could evenly elevate the temperature of the building envelop. Hot spots with thermal contrast of over $4^{\circ} \mathrm{C}$ could be considered as debonds [6]. Hence this project adopts passive IRT to perform debond detection on building envelop.

Maldague and Moore proposed that "the thermal response of a thick, semi-finite, insulating, opaque and solid composite materials" after heating can be defined by this 3-D heat conduction equation [7]:

$$
C \rho \frac{\partial T}{\partial t}=\frac{\partial}{\partial x}\left(k_{x} \frac{\partial T}{\partial x}\right)+\frac{\partial}{\partial y}\left(k_{y} \frac{\partial T}{\partial y}\right)+\frac{\partial}{\partial z}\left(k_{z} \frac{\partial T}{\partial z}\right)+w(x, y, z)
$$

where $\mathrm{C}$ represents specific heat capacity $\left(\mathrm{J} \mathrm{kg}^{-1} \mathrm{~K}^{-1}\right), \rho$ represents density $\left(\mathrm{kg} \mathrm{m}^{-3}\right), \mathrm{T}$ represents temperature in degree kelvin (K), t represents time lapse, $\mathrm{k}_{\mathrm{x}}, \mathrm{k}_{\mathrm{y}}, \mathrm{k}_{\mathrm{z}}$ represent the anisotropic thermal conductivities in three major directions of heat transfer in the material, and w represents the generating rate of energy per unit volume in the medium.

Equation (1) could be shortened into equation (2) where ' $w$ ' could be eliminated in thermal non-destructive testing:

$$
C \rho \frac{\partial T}{\partial t}=\frac{\partial}{\partial x}\left(k_{x} \frac{\partial T}{\partial x}\right)+\frac{\partial}{\partial y}\left(k_{y} \frac{\partial T}{\partial y}\right)+\frac{\partial}{\partial z}\left(k_{z} \frac{\partial T}{\partial z}\right)
$$

If $k_{x}, k_{y}, k_{z}$ in all three major directions are the same and the thermal diffusivity a (unit in $\left.m^{2} s^{-1}\right)=k(C \rho)^{-1}$, equation (2) can be further shortened to equation (3).

$$
\frac{\partial^{2} T}{\partial x^{2}}+\frac{\partial^{2} T}{\partial y^{2}}+\frac{\partial^{2} T}{\partial z^{2}}=\frac{1}{\alpha} \frac{\partial T}{\partial t}
$$


Both equation (2) and (3) are two recognizable phenomena in debond area and intact area after heating correspondingly. Equation (2) results in an uneven and Gaussian-like profile of surface temperature (i.e. low-high-low profile) which indicates debond. Equation (3) shows a reasonably even temperature distribution that indicates no debond.

Lai et al. validated size estimation of debond, which is hidden under rendering and mosaic tiles, in building envelop using quantitative IRT based on the above equations [3].

3D building model could be combined with thermal images to show temperature peaks and its extent. Borrmann, Elseberg, and Nuchter proposed a methodology of combining visual camera, IRT camera and laser scanner in a robot for 3D thermal model formation [8]. Such 3D reconstruction was performed by bundle adjustment. Using registration algorithms could align scans from different poses. In the experiment, both infrared camera and visual camera need to be calibrated. During the data collection, intrinsic calibration is performed to align camera coordinates system to the world coordinates system, followed by extrinsic calibration to align image coordinates system to the scanner's coordinate system. Thermal images then projected to the laser scanning data according to the distance and size, and registered. Another approach is to perform a texture mapping on a 3D model [9]. A methodology of automatic thermal infrared texturing is proposed. Thermograms and 3D model will be spatial referencing by matching line segments, control points or surfaces.

In this project, temperature contrasts of each pixel in thermal images will be transformed in a database for machine learning in order to develop a Python program that can automatically detect debond in a thermal image. A binary image indicating debonds will be exported and converted into a debond point cloud to be used in a BIM model.

\section{Methodology}

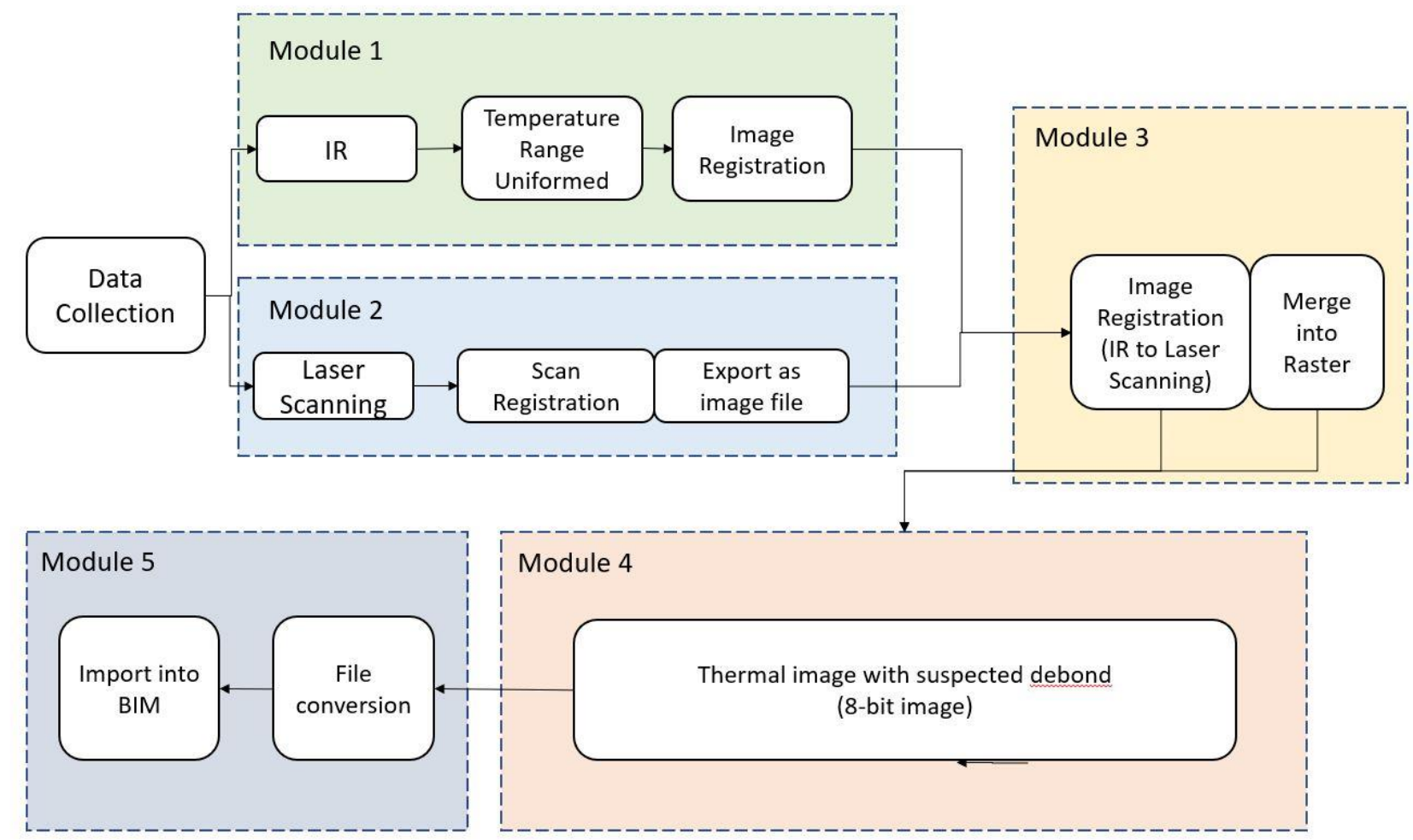

Fig. 1. Proposed Project Workflow

The proposed project workflow, shown in Fig. 1, consists of 5 main modules: Data Collection (Module 1 \& 2), IRT Image Registration (Module 3), Image Processing (Module 4) and File conversion (Module 5). In Module 1, thermal images of the selected building will be captured according to the conditions required in HKCl: TM1 [10]. To ensure the accuracy in image registration in Module 3, there are additional requirements in data capture, including the angle of elevation and required percentage of overlapping. After collecting thermal images, the temperature range of each images should be unified and aligned with the corresponding visual image by applying perspective correction in a Matlab program for Module 3. In Module 2, scan registration will be performed if multiple scans are captured in order to cover the whole building envelop. Then a section plan of the building envelop will be exported for Module 3.

Image registration will be performed in Module 3, where uniformed thermal images will register according to the section plan obtained from laser scanning data. Visual images, which are aligned with corresponding thermal images, will be used to perform registration with the section plan using ArcGIS Pro. To register the visual images, at least 4 control 
points will be selected to perform projective correction. After visual image registration, thermal images will be imported and will be registered to the corresponding position. All the registered thermal images will be merged into a 8-bit raster format (i.e. .tif format) for Module 4.

A program will be developed using Python programming language in Module 4. Sample thermal images collected in a field experiment will be used to develop a database. In the program, the database, which indicates temperature data in debond area and intact area, will be used to perform logistic regression for training. After training, test data will be imported into the program for debond detection. A binary image indicating the debond area of building envelop will be produced.

In Module 5, the binary image indicating debond area will be transformed into point cloud and registered with the point cloud collected in Module 1 for location. In order to facilitate quantity take-off in BIM model, point cloud with debond will be used to create corresponding BIM objects by Dynamo scripts, which can provide figures to perform cost estimation.

\section{Results and discussion}

A building located in Kwun Tong District was selected, and both thermal data and point cloud data were collected on $26^{\text {th }}$ March 2019. In this module, a FLIR T650sc infrared camera and a FARO Focus M70 laser scanner were used to capture thermal images and point cloud data respectively.

\begin{tabular}{|l|l|}
\hline Detector type & Uncooled microbolometer \\
\hline Thermal sensitivity (NETD) & $<0.02^{\circ} \mathrm{C}$ \\
\hline Accuracy & $\pm 1^{\circ} \mathrm{C}$ or $\pm 1 \%$ of reading for limited temperature range \\
\hline Resolution & $640 \times 480$ \\
\hline Spectral range & $7.5-13.0 \mu \mathrm{m}$ \\
\hline Frame rate & Max. $30 \mathrm{~Hz}$ \\
\hline Field of View & $25^{\circ} \times 19^{\circ}$ \\
\hline
\end{tabular}

Table 1. Specifications of IR camera used in the project

\begin{tabular}{|l|l|}
\hline Unambiguity Interval & $614 \mathrm{~m}$ for up to $0.5 \mathrm{mil}$ pts/sec \\
& $307 \mathrm{~m}$ at $1 \mathrm{mil} \mathrm{pts} / \mathrm{sec}$ \\
\hline Range (90\% Reflectivity) & $0.6-70 \mathrm{~m}$ \\
\hline Max. Measurement Speed & Up to $1 \mathrm{mil}$ pts $/ \mathrm{sec}$ \\
\hline Range error & $\pm 1 \mathrm{~mm}$ \\
\hline Angular Accuracy & $19 \mathrm{arcsec}$ \\
\hline 3D Point Accuracy & $2 @ 10 \mathrm{~m} 3.5 @ 25 \mathrm{~m}$ \\
\hline Field of View & $300^{\circ}$ vertical $/ 360^{\circ}$ horizontal \\
\hline Max. Scan Speed & $97 \mathrm{~Hz}$ (vertical) \\
\hline
\end{tabular}

Table 2. Specifications of laser scanner used in the project

\begin{tabular}{|l|l|}
\hline Date & 26 March 2019 \\
\hline Time & $09: 00-13: 00$ \\
\hline Venue & Kwun Tong \\
\hline Average Temperature & $20.8^{\circ} \mathrm{C}-24.6^{\circ} \mathrm{C}$ \\
\hline Mean Relative Humidity & $85 \%$ \\
\hline Total Rainfall & $0 \mathrm{~mm}$ \\
\hline Cloud Coverage & $86 \%$ \\
\hline Wind Speed & $26.4 \mathrm{~km} / \mathrm{h}$ \\
\hline
\end{tabular}

Table 3. Summary of weather condition on the date of data collection in Kwun Tong

There is a limitation during data collection. Since unmanned aircraft systems (UAS) were not allowed to be flown over populated areas, thermal camera could only be set on the pedestrian level opposite to the target building. Hence, to capture the upper level of the target building, the angle of elevation was relatively large.

Module 1, 2 and 3 were successfully performed and a thermal image of the whole building was exported. From Fig 2, distortions were found in the upper floors of the buildings, which are mainly due to the limitations in angle of elevation when collecting thermal images of the buildings. 


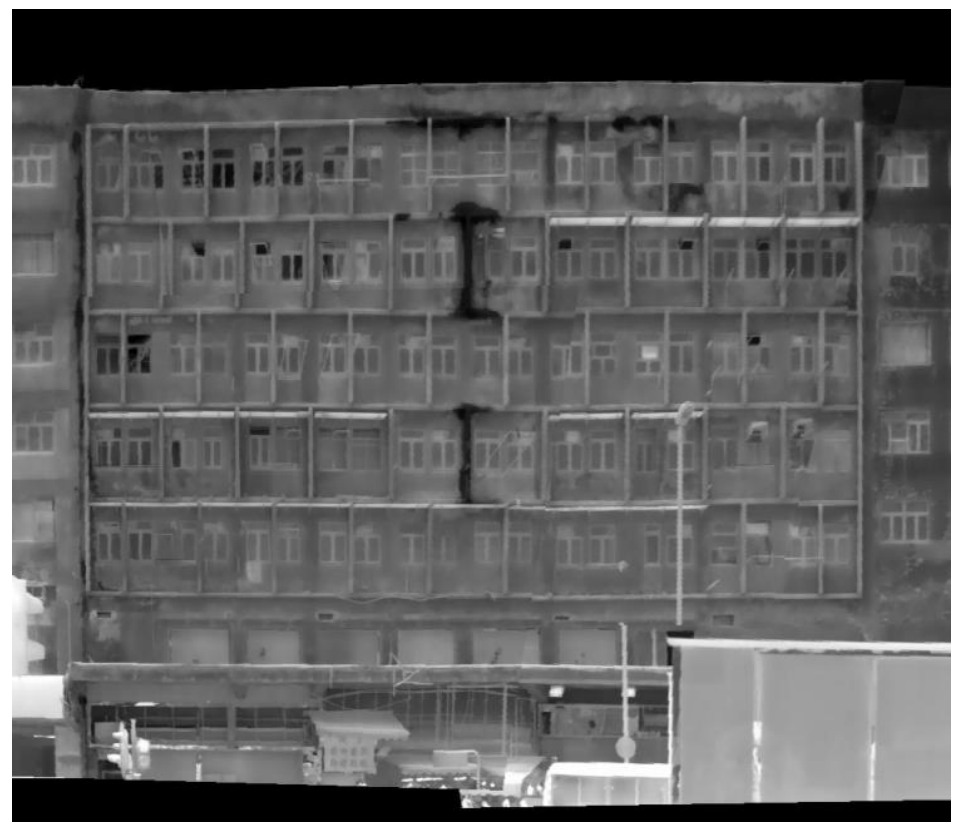

Fig 2. Thermal image of the whole building

Module 4 and 5 are still in progress. In Module 4, thermal images of a reinforced concrete wall were captured in every 5 mins between 08:00 and 21:00. The reinforced concrete wall was divided into 8 parts. In each part, 5 polystyrene plates were embedded in different cover depths.

\begin{tabular}{|l|l|}
\hline Date & $6^{\text {th }}$ February 2018 \\
\hline Time & $08: 00-21: 00$ \\
\hline Venue & Shek Mun, Shatin \\
\hline Average Temperature & $7.9^{\circ} \mathrm{C}-14.2^{\circ} \mathrm{C}$ \\
\hline Humidity & $40 \%-66 \%$ \\
\hline Average Ambient Gamma Radiation & $0.12 \mathrm{MS}$ (Tai Mei Tuk) \\
\hline Cloud Coverage & $68 \%$ \\
\hline Wind Speed & $25 \mathrm{~km} / \mathrm{h}$ \\
\hline
\end{tabular}

Table 3. Summary of weather condition on the date of sample data collection in Shek Mun

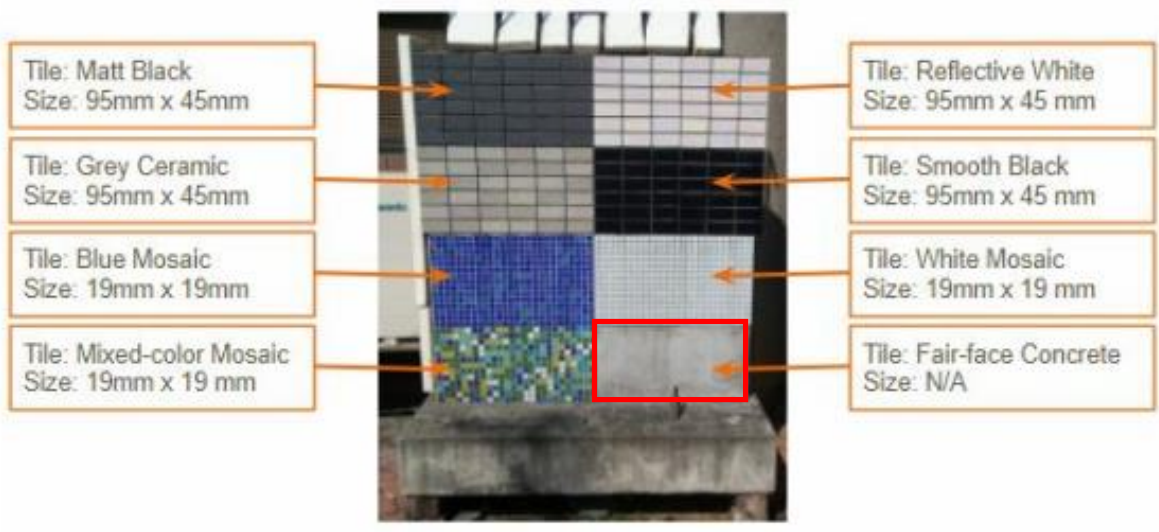

Fig 3. The reinforced concrete wall used 


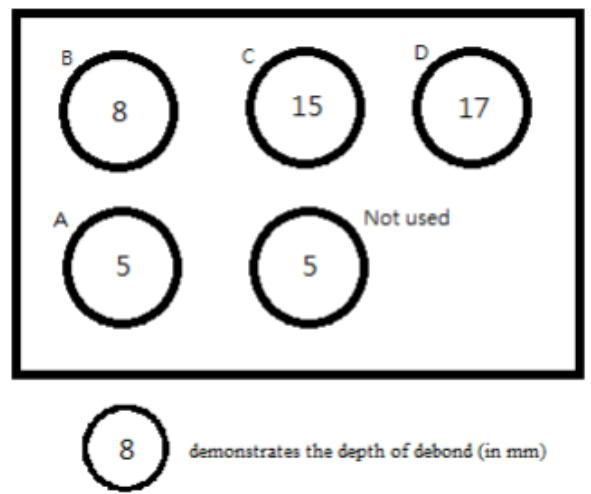

Fig 4. Demonstration of debonds with corresponding cover depth

Only the concrete part was used to develop the database for data collected in Kwun Tong. One thermal image taken in morning session and one thermal image taken in night session were selected. Thermal contrast between debond area and intact area in the selected thermal images was calculated and then imported into a database to be used in a Python program. After developing a database, a sample thermal image taken in another survey day was imported into the program to perform debond detection. From Fig 5., the shapes of the embedded debonds can be detected and its sizes varies according to the cover depth.

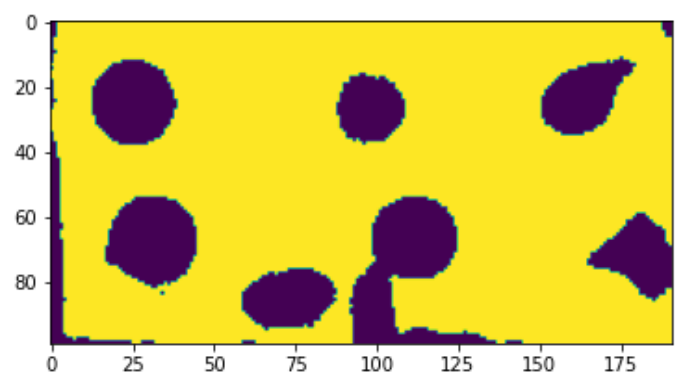

Fig 5. Debond detection performed in Python program

For Module 5, a sample binary image indicating debonds was converted into a point cloud format and imported into a BIM model (Fig 6.). In this stage, a Dynamo script is needed in order to convert each debond into BIM object, which allows quantity take-off in BIM modelling.

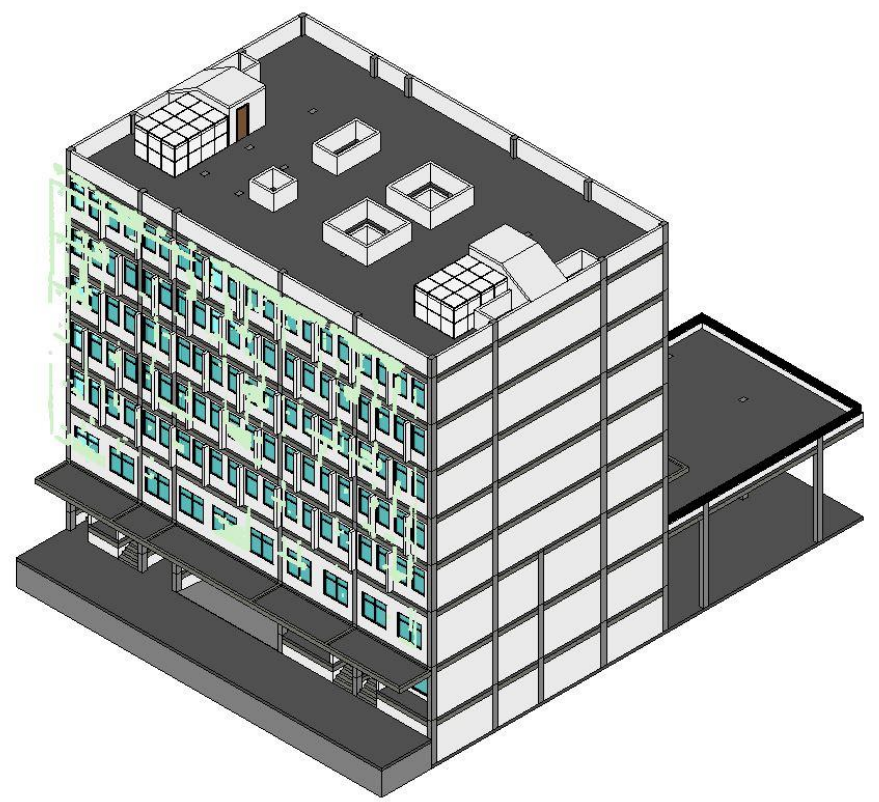

Fig 6. Debond point cloud (in light green color) shown on a BIM model. 


\section{Future works to be done}

Since this is an ongoing project, there are several works to be done in the future. Firstly, the database used for python program development will be improved. In this stage, the database for Python program is developed by evaluating the relation between the thermal contrast in morning session and that in night session. Relation between thermal contrast in a thermal image and that in a thermal image taken after 5 mins will be studied and tested in the Python program in the future. For Module 5, a Dynamo script will be developed in order to convert debond point cloud into BIM objects automatically.

\section{REFERENCES}

[1] Buildings Department. Code of Practice for Mandatory Building Inspection Scheme and Mandatory Window Inspection Scheme, Hong Kong, 2012.

[2] HOKLAS. HOKLAS Supplementary Criteria No.19 Construction Materials Test Category - Accreditation of Diagnostic Tests on Concrete, Hong Kong, 2018.

[3] Lai W.L., Lee K.K., Poon C.S. "Validation of size estimation of debonds in external wall's composite finishes via passive Infrared thermography and a gradient algorithm". Construction and Building Materials; 87: pp. 113-124, 2015.

[4] Development Bureau. "Adoption of Building Information Modelling for Capital Works Projects in Hong Kong". Technical Circular (Works) No. 9/2019, Hong Kong, 2019.

[5] Lehmann B., Ghazi Wakili K., Frank T., Vera Collado B., Tanner C. "Effects of individual climatic parameters on the infrared thermography of buildings". Applied Energy; 110: pp. 29-43, 2013)

[6] Maldague X. Nondestructive evaluation of materials by infrared thermography. London: Springer; 1993.

[7] Maldague X., Moore P. Infrared and thermal testing ( $3^{\text {rd }}$ ed.) American Society for Nondestructive Testing, 2001)

[8] Borrmann D., Elseberg J., Nuchter A. Thermal 3D Mapping of Building Facades; 193, 2012.

[9] Hoegner L., Stilla U. "Building façade object detection from terrestrial thermal infrared image sequences combining different views". PIA15+HRIGI15 - Joint ISPRS conference, Germany, 2015.

[10] Hong Kong Concrete Institutue. HKCl: TM1 Detection of Building Surface Defect by Infrared Thermography, Hong Kong, 2009. 